\title{
ESTADO, DESENVOLVIMENTO ECONÔMICO E POLÍTICAS PÚBLICAS: UMA ANÁLISE DA LEI N. 12.858/2013 E O FINANCIAMENTO DA EDUCAÇÃO NO BRASIL
}

Francisco Cláudio Oliveira Silva Filho Cynara Monteiro Mariano

\section{INTRODUÇÃO}

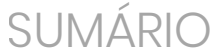

As políticas públicas, o projeto de Estado social e os direitos sociais são interligados conceitualmente a facetas do mesmo processo histórico. Essas noções partem do reconhecimento da existência de necessidades humanas fundamentais e que demandam ações políticas efetivas para seu atendimento.

No Brasil, a positivação de direitos sociais remonta à Constituição de 1934. Mas é a partir do contexto social e jurídico inaugurado com a promulgação da Constituição de 1988 que podemos compreender as políticas públicas como meios para efetivação de direitos, especialmente de caráter social. A Constituição de 1988 foi precedida por um amplo processo de mobilização social, pela luta contra a ditadura militar e por reivindicações pela democratização da política. Essas circunstâncias, dentre outros fatores, fizeram com que o texto constitucional expressasse um conjunto de reivindicações, necessidades, reformas estruturais e projetos coletivos, consubstanciados na forma de direitos sociais, como educação, saúde, alimentação, proteção aos trabalhadores, moradia, reforma agrária, proteção do meio ambiente e previdência social.

Para além da estreiteza das concepções liberais do direito, o constitucionalismo social, característico da atual constituição brasileira, reclama a intervenção do Estado para garantia e efetivação de direitos. A escolha de políticas públicas, como meio para efetivação de direitos sociais, exige necessariamente uma decisão política e a intervenção 
deliberada do Poder Público. Dentre os direitos sociais enumerados na Constituição de 1988, especialmente no artigo 60, o direito à educação aparece de forma relevante. Também é assumida como direito de todos e dever do Estado e da família e que será promovida e incentivada com a colaboração da sociedade, como dito no artigo 205 da Constituição. Esses elementos trazidos pelo texto constitucional sobre a educação exigem uma atuação deliberada do Estado, por meio de ações políticas concretas.

Além do reconhecimento da educação como direito social, a Constituição Federal, com alterações da Emenda Constitucional $n$. 59, de 2009, determina a elaboração de um plano nacional decenal para educação. Esse plano deve conduzir, dentre outros objetivos, ao estabelecimento de meta de aplicação de recursos públicos em educação como proporção do Produto Interno Bruto (PIB), conforme o artigo 214, inciso VI, da Carta Constitucional.

A intervenção do Estado para concretização de direitos sociais implica necessariamente na aplicação de recursos públicos. Assim, com objetivo de garantir recursos para o cumprimento das metas constitucionais, foi promulgada a Lei n. 12.858, de 9 de setembro de 2013, que trata da destinação, para as áreas de educação e saúde, de parcela da participação no resultado ou da compensação financeira pela exploração de petróleo e gás natural. A finalidade dessa disposição é cumprir as metas constitucionais do Plano Nacional de Educação (PNE). Essa lei foi promulgada no contexto da descoberta de gigantescas reservas de petróleo e gás natural na camada do pré-sal, localizada em vasta região do litoral brasileiro. Assim, discutiremos a relação entre políticas públicas e efetivação do direito social à educação no Brasil, tendo como foco a análise da Lei n. 12.858/2013, especialmente quanto à destinação dos royalties oriundos da exploração do petróleo para o cumprimento das metas de recursos para o PNE.

\section{ESTADO SOCIAL E POLITIICAS PÚBLICAS}

A temática das políticas públicas é oriunda da Ciência Política e da Ciência da Administração Pública e, na Ciência do Direito, tem sido objeto 
da Teoria do Estado e em disciplinas de Direito Público. Portanto, conforme Bucci (2006), analisar políticas públicas como objeto de estudo do direito é necessariamente realizar uma abertura para interdisciplinaridade.

O paradigma do positivismo jurídico, típico da formação do Estado liberal, foi fundamental para delimitação e autonomia da ciência jurídica, porém o desafio atual, na compreensão de Bucci (2006), é superar o problema do esvaziamento do Direito Público, na sua função de articulação entre Estado, Administração Pública e sociedade. O positivismo jurídico levou a um processo de distanciamento em relação a uma realidade em permanente transformação. Nesse sentido, a mesma autora defende que o instrumental jurídico liberal e positivista não é o adequado para captar o caráter eminentemente dinâmico e funcional das políticas públicas (BUCCl, 1996). É necessário, portanto, compreender as políticas públicas, no contexto das transformações sociais, que implicaram em redefinições do papel do Estado, e que têm, atualmente, como uma de suas principais funções, a efetivação de direitos sociais.

As políticas públicas, assim como os direitos sociais, são realidades que surgem com a formação do Estado social. Porém, é importante ressalvar que quando analisamos as mudanças que ocorrem no Estado, não significa a ocorrência de uma ruptura estrutural ou a supressão de uma forma de Estado por outra, no caso o Estado social sobre o Estado liberal. Ao contrário, o Estado moderno mantém, ao longo de sua história, a mesma essência.

O Estado é caracterizado, em última instância, na compreensão de Weber (2011), pelo monopólio legítimo do exercício da força ou da violência. No sentido exposto pelo sociólogo alemão, a política, que tem no Estado moderno a sua principal forma de organização e expressão, é entendida como conjunto de esforços com objetivo de influenciar o poder dentro do Estado (WEBER, 2011). Em sentido semelhante, Bobbio (2003) entende o poder como capacidade que um sujeito possui de condicionamento e determinação do comportamento de outro indivíduo. Tal como Max Weber, Norberto Bobbio estabelece como critério mais adequado para distinguir as diversas formas de poder os meios utilizados para obter os efeitos desejados. Assim, para Bobbio (2003), o poder político é delimitado pelo uso da força como meio para alcançar seus fins, 
ainda que em última instância. Por outro lado, para o jurista italiano, há uma passagem do poder de fato, em última instância a força direta, para o poder de direito. É a manutenção do exercício do poder, ou seja, sua continuidade, que determina a juridicidade do exercício do poder, e não apenas sua institucionalização sob a forma de Estado.

Ocorre que a partir do século XIX, especialmente na primeira metade do século $X X$, diversas transformações sociais, econômicas e jurídicas conformaram novas funções para o Estado, como o reconhecimento de demandas sociais na forma de direitos e políticas públicas. A afirmação de necessidades coletivas, consubstanciada em direitos sociais, é uma das principais características do direito no início do século XX. As revoluções liberais burguesas foram fundamentais para o reconhecimento e positivação de direitos e garantias individuais, como as liberdades de ir e vir, de pensamento, de expressão, de associação etc. No entanto, as contradições do desenvolvimento econômico e social, especialmente depois da Revolução Industrial, implicaram em novos e complexos direitos. Para além de aspectos individuais, os conflitos sociais geraram demandas e necessidades como moradia, proteção aos trabalhadores, previdência social, educação e saúde pública.

O conflito social, especialmente entre classes sociais proprietárias e de trabalhadores, típica da sociedade capitalista, não é algo alheio ao direito. Ao contrário, faz parte do seu processo de desenvolvimento histórico. Bucci (2006) aponta que os conflitos são um aspecto do constitucionalismo no século XX. Para autora, "[...] os conflitos sociais não são negados e mascarados sob o manto de uma liberdade individual idealizada. [...] ganham lugar privilegiado, nas arenas de socialização política." (BUCCl, 2006, p. 6). O contexto de conflitos sociais e políticos gerou a conformação do Estado social, que pode ser definido, conforme Kerstenetzky (2012, p. 61), “[...] como um conjunto histórico e institucionalmente moldado de intervenções públicas visando à promoção do bem-estar e envolvendo redistribuição".

A ideia de um Estado social não é isenta de crítica. Bauman (2014) destaca o aspecto contraditório da formação do Estado social que teria o real objetivo de manter os trabalhadores em condições mínimas de presteza. Nesse sentido, o Estado social, durante um determinado 
período da história, passou a ser defendido tanto por forças de esquerda como de direita. Além disso, o Estado precisa proteger o capitalismo das próprias contradições e consequências fruto da voracidade de lucro (BAUMAN, 2014). Para isso, com suas novas funções, passou a reconhecer necessidades sociais, estabelecendo limites e proteção jurídica para demandas dos trabalhadores, sob pena de tornar insustentável para o desenvolvimento do capitalismo os conflitos entre as classes sociais.

De toda forma, a caracterização do Estado moderno extrapola sua essencialidade de uso da força de forma organizada e legítima. Ao longo do século XX, em especial depois das duas Guerras Mundiais, o Estado passou por profundas redefinições. Por um lado, a crise capitalista em 1929 e da destruição das principais economias mundiais em razão das guerras, fez com que os grupos políticos dominantes reavaliassem o papel do Estado no desenvolvimento econômico. Por outro lado, os movimentos reivindicatórios de trabalhadores e a ocorrência de processos revolucionários, como do México (1910) e da Rússia (1917), geravam tensionamentos e contradições que tiveram expressões nas concepções de Estado e de constituição. Exemplo disso é a constituição mexicana de 1917 que incorporou, pela primeira vez, direitos sociais, resultados dos avanços da revolução precedente.

O paradigmados direitos sociaisestárelacionadonecessariamente com prestações positivas do Estado, o que significa um distanciamento das teorias liberais do direito. Desse modo, Bucci (2006) entende que não há um modelo jurídico de política social apartado do modelo de políticas públicas econômicas. Ao contrário, a nova compreensão sobre o direito e as políticas públicas tem a mesma origem histórica, que é a formação do Estado intervencionista.

Seguindo a classificação de Bonavides (2003) para o desenvolvimento histórico dos direitos humanos, podemos estabelecer uma relação entre a concepção de Estado liberal abstencionista, que corresponde às teorias liberais predominantes no século $\mathrm{XIX}$, e a afirmação dos chamados direitos de primeira geração, que exigem uma prestação negativa do Estado. Por outro lado, a partir das novas demandas e necessidades surgidas no início do século XX, grupos e classes sociais reivindicam um Estado intervencionista, provedor de uma prestação 
positiva para efetivação de direitos sociais, ou de direitos de segunda geração.

Isso demonstra um esgotamento das concepções liberais sobre Estado. Em termos históricos, o liberalismo clássico cumpriu a função de afirmação de direitos de liberdade, especialmente para classe burguesa. No entanto, Martins (2011, p. 144-145) entende que "[...] para as pessoas desprovidas de condições mínimas para usufruir a liberdade [...] o Estado Liberal é inútil. $\mathrm{O}$ avanço foi inevitável: a substituição do Estado Liberal pelo Estado Social, do Estado de Polícia pelo Estado Prestador de Serviços".

As mudanças nas teorias do Estado e do Direito implicam na afirmação, conforme Medauar (2003), que as atividades as quais são essenciais à coletividade, como é o atendimento aos direitos sociais, não podem ficar subordinadas apenas ao livre mercado. Assim, há uma oposição entre atendimento de demandas sociais e liberalismo. Medauar (2003) destaca a atualidade do pensamento da Escola Francesa de Direito Administrativo, no início do século $X X$, ao defender a noção de serviço público (conceito contido na expressão política pública) como expressão uma atividade submetida não às únicas leis do mercado, mas a um regime jurídico de Direito Público, que impõem exigências ao próprio Estado. Portanto, é o elemento de garantia de proteção às classes menos favorecidas.

Em outra perspectiva, Chauí (2007, p. 27) também tece críticas ao que chama do "[...] encolhimento do espaço público e o alargamento do espaço privado sob a ação da economia e dos governos chamados neoliberais". O neoliberalismo implica na destruição de direitos econômicos, sociais e políticos garantidos pelo poder público, em proveito dos interesses privados. A filósofa define o que seria a substituição da política por questões aparentemente técnicas, como efeito da "ideologia da competência". Assim, a política é considerada uma questão técnica que passa a ser abordadas por especialista competentes, cabendo ao cidadão, segundo a visão crítica de Chauí (2007), confiar na competência dos técnicos e reduzir sua participação política ao momento do voto nas eleições. Em sentido semelhante, Nunes (2011) afirma a incompatibilidade do neoliberalismo com as políticas sociais, direitos sociais e a própria democracia. A ideologia neoliberal aponta como uma necessidade a 
redução do estado ao estado mínimo. Mas não esconde que ele tem de ser suficientemente forte para realizar a privatização de todos os serviços públicos (NUNES, 2011).

Para o constitucionalista português, o ideário liberal nega o objetivo das constituições modernas de redução das desigualdades sociais. Segundo ele, "[...] as políticas que buscam realizar a justiça social distributiva são sempre encaradas como um atentado contra a liberdade individual." (NUNES, 2011, p. 129). Essa noção é um retrocesso à tese liberal de que o mercado realiza, por si, a liberdade, a eficiência econômica e a equidade social. Avelãs Nunes reafirma sua crítica ao liberalismo e aos neoliberais contemporâneos de forma contundente. O avanço de políticas neoliberais, além destruírem as políticas sociais, é contrária à cultura democrática do Estado social e ao sistema de seguridade pública, pregando o retorno ao individualismo econômico e social. Para Nunes (2011, p. 131), "[...] os neoliberais voltam, assim, as costas à cultura democrática e igualitária da época contemporânea, caracterizada não só pela afirmação da igualdade civil e política para todos, mas também pela busca da redução das desigualdades entre os indivíduos no plano económico e social". Ou seja, no objetivo mais amplo de libertar a sociedade e os seus membros da necessidade e do risco, objetivo que está na base dos sistemas públicos de segurança social.

Portanto, a afirmação do Estado social - e consequentemente a crítica às concepções liberais e neoliberais - é necessária para o reconhecimento dos direitos sociais e das políticas públicas. O elemento que caracteriza o Estado social, no qual são expressados direitos sociais, é "[...] a existência de um modo de agir dos governos ordenado sob a forma de políticas públicas, um conceito mais amplo que o de serviço público, que abrange também as funções de coordenação e de fiscalização dos agentes públicos e privados." (BUCCl, 1996, p. 135).

As políticas públicas são expressão concreta das diretrizes políticas mais gerais do Estado social. Nesse sentido, a análise das transformações e concepções sobre a política e o Estado evidencia que a fruição dos direitos sociais implica na ampliação de medidas concretas do Poder Público. 
O Estado se alarga cada vez mais "[...] de forma a disciplinar o processo social, criando modos de institucionalização das relações sociais que neutralizem a força desagregadora e excludente da economia capitalista e possam promover o desenvolvimento da pessoa humana." (BUCCl, 2006, p. 4). Por tudo isso, podemos concluir pela relação intrínseca entre a defesa do Estado social e as condições para realização de políticas públicas. Essas políticas, por sua vez, são fundamentais para efetivação dos direitos sociais.

\section{POLÍTICAS PÚBLICAS E DIREITOS SOCIAIS}

Políticas públicas são um meio de efetivação de direitos sociais. Quando tratamos de políticas públicas, estamos afirmando, seguindo a compreensão de Pereira (2013) uma política que tem por definição o fato de ser pública, ou seja, de todos. Isso implica que a atuação política não será direcionada ou promovida em razão de um indivíduo ou por interesses particulares, mas sim para o atendimento de necessidades sociais.

Nesse contexto, também surge a discussão sobre as políticas públicas, em especial as políticas sociais, mais diretamente voltadas para as demandas de natureza coletivas. É o sentido proposto por Demo (1984), quando afirma que a política social deve ser contextualizada como um projeto planejado para enfrentar as desigualdades sociais. Da mesma forma, os direitos sociais são resultados do reconhecimento de legítimas demandas de grupos e classes sociais. Para a efetivação desses direitos é imprescindível a intervenção do Estado, de forma que se possam realizar situações de igualdade material.

Bucci (2006) entende as políticas públicas como um programa ou conjunto articulado de ações e governamentais com escopo de concretizar objetivos de ordem pública, ou em sentido jurídico, concretizar direitos. Da mesma forma, Pereira (2009) afirma que as políticas públicas visam à concretização de direitos sociais e que esses direitos só têm aplicabilidade por meio das políticas públicas que, por sua vez, são operacionalizadas por meio de programas, projetos e serviços. Os direitos sociais são entendidos 
como conquistas de determinados grupos e classes sociais e positivadas pelo direito.

Em uma análise que ressalta aspectos jurídicos e formais, Grinover (2009) entende políticas públicas como conjunto de atividades do Estado tendentes a seus fins, de acordo com metas a serem atingidas. Trata-se, assim, de um conjunto de normas (Poder Legislativo), atos (Poder Executivo) e decisões (Poder Judiciário) que visam à realização dos fins primordiais do Estado.

O surgimento dos direitos sociais deu-se, no século XX, por meio da existência de um Estado social forte e atuante. Assim, nos termos de Pereira (2013), os direitos sociais reclamam a atuação do Estado na sociedade e a proteção pública dos direitos sociais. Portanto, "[...] eles [direitos sociais] não se reduzem a um mero sistema institucional de garantias de prevenção e de assistência, [...] mas devem legitimar e dar cobertura legal às políticas sociais universais mediante as quais eles se materializam." (PEREIRA, 2013, p. 56). Dessa forma, as políticas públicas são resultadas da tomada de decisões políticas. Essa assertiva considerada que o reconhecimento e atendimento das necessidades humanas, na forma de direitos sociais, não cabem à esfera privada, como o mercado. As concepções teóricas que defendem que a "mão invisível do mercado" é suficiente para o atendimento das necessidades sociais fazem crer que o papel do mercado é de "[...] agência-mor de provisão, e o consumidor (e não o cidadão) como alvo de satisfação, inclusive públicas." (PEREIRA, 2009, p. 41). Assim, a discussão sobre a realização das políticas públicas como meio de concretização de direitos sociais esbarra frontalmente com as concepções liberais da política e da economia.

Como forma de atendimento de necessidades sociais, a relevância e atenção que o Estado e a sociedade proclamam sobre os direitos sociais podem variar por questões históricas, econômicas e culturais. As demandas sociais não são abstratas, mas são resultadas de contextos históricos concretos. No caso do Brasil, a educação é um dos direitos sociais que a sociedade mais reclama atenção. A primeira vez que a educação foi tratada como direito social no Brasil foi na Constituição de 1934 que, apesar de contemplar em seu texto o interesse de grupos conservadores, especialmente ligados à Igreja Católica, conforme Andreotti 
(2006), procurou atender demandas sociais, defendendo a educação como direito de todos e dever do Estado. Também é nesse período que se inaugura o entrelaçamento das políticas de desenvolvimento social e a efetivação do direito à educação. Porém, é a partir da Constituição de 1988 e nas décadas posteriores que haverá a possibilidade de universalização da educação no Brasil.

\section{A DESCOBERTA DO PRÉ-SAL, A LEI N. 12.858/2013 E (A PROMESSA) DA EFETIVAÇÃO DO DIREITO À EDUCAÇÃO NO BRASIL}

Como analisado, há uma imbricada relação entre Estado e direitos sociais, sendo as políticas públicas um meio para concretização desses direitos. No Brasil, Kerstenetzky (2012) afirma a existência de três períodos de ampliação dos direitos sociais no Brasil. O primeiro que denomina de bem-estar corporativo, entre 1930 e 1964, com a implementação das legislações trabalhistas e previdenciárias; o segundo, denominado de universalismo básico, de 1964 a 1984, quando se estendeu, de modo diferenciado, a cobertura previdenciária para grupos sociais tradicionalmente excluídos e se criou um sistema de saúde combinando setor privado e público; e, por fim, o período pós-1988, com a institucionalização da assistência social, a fixação de um mínimo social, a extensão da cobertura previdenciária não contributiva, a criação do Sistema Único de Saúde (SUS) e a política de valorização do saláriomínimo, prenunciando, com limitações, um universalismo estendido.

Desde a década de 1930, as constituições brasileiras incorporaram a questão da educação em um projeto de desenvolvimento do País. Na Constituição de 1934, no artigo 149, afirmava-se que a educação é direito de todos e deve ser ministrada, pela família e pelos Poderes Públicos. Além disso, deveria possibilitar eficientes fatores da vida moral e econômica da Nação, e desenvolva num espírito brasileiro a consciência da solidariedade humana.

A atual Constituição brasileira também aborda a questão da educação no sentido de relacioná-la com o desenvolvimento 
socioeconômico do País. A Constituição Federal de 1988 definiu, no artigo 6 6, a educação como direito social. Já no artigo 205, afirma ser um direito de todos e dever do Estado e da família, e será promovida e incentivada com a colaboração da sociedade, visando ao pleno desenvolvimento da pessoa, seu preparo para o exercício da cidadania e sua qualificação para o trabalho.

Além de afirmar a educação como um direito social, a Constituição detalhou diversos outros aspectos, como princípios do ensino (art. 206), princípios das universidades (art. 207), o dever do Estado em relação aos diversos níveis de educação e ao cumprimento de metas (art. 208), ensino em instituições privadas (art. 209), conteúdos mínimos para o ensino fundamental (art. 210) e repartição de competência no sistema educacional (art. 211).

Porém, merece destaque a determinação de aplicação orçamentária e o planejamento da educação, exposta do artigo 212 ao 214 , especialmente o estabelecimento de PNE. O presente artigo trata em especial no inciso VI, que foi incluído pela Emenda Constitucional n. 59, de 2009. $O$ artigo dispõe o seguinte:

Art. 214 A lei estabelecerá o plano nacional de educação, de duração decenal, com o objetivo de articular o sistema nacional de educação em regime de colaboração e definir diretrizes, objetivos, metas e estratégias de implementação para assegurar a manutenção e desenvolvimento do ensino em seus diversos níveis, etapas e modalidades por meio de ações integradas dos poderes públicos das diferentes esferas federativas que conduzam a:

I - erradicação do analfabetismo;

II - universalização do atendimento escolar;

III - melhoria da qualidade do ensino;

IV - formação para o trabalho;

V - promoção humanística, científica e tecnológica do País;

VI - estabelecimento de meta de aplicação de recursos públicos em educação como proporção do produto interno bruto. (BRASIL, 2009). 
Em 1996, foi promulgada a Lei de Diretrizes e Bases da Educação Brasileira (LDB), Lei n. 9.394. A LDB, em conjunto com o PNE, corroborou para estruturar o sistema educacional do País e definir de forma objetiva o financiamento para o cumprimento das metas prevista na Constituição. Com o estabelecimento de metas de aplicação de recursos orçamentários proporcionais ao produto interno bruto (PIB), movimentos sociais, estudantis e sindicais em defesa da educação passaram a reivindicar participação no processo de elaboração dos planos nacionais de educação, além de exigir aplicação dos recursos financeiros necessários para efetivação do direito social.

Quase dez anos depois da promulgação da LDB, um fato novo reacendeu os debates sobre os investimentos do Estado em políticas públicas educacionais. Em 2005, ocorreu a descoberta de imensas reservas de petróleo e de gás natural no litoral brasileiro, localizadas na camada do pré-sal. As estimativas iniciais, logo depois da descoberta dessas jazidas de petróleo, colocaram o Brasil como uma das maiores reservas petrolíferas do mundo. Essa expectativa gerou profundas disputas políticas e jurídicas em torno da distribuição dos recursos que seriam oriundos da exploração do pré-sal. Diante da magnitude das novas reservas, discutiu-se no âmbito do Governo Federal e do Congresso Nacional a necessidade de alterações no marco legal sobre o petróleo. Cabe ressaltar o intenso debate que ocorreu sobre a destinação dos royalties oriundos da exploração do petróleo.

Os royalties são participações nos recursos financeiros da extração do petróleo estabelecidos para os estados e municípios produtores como forma compensação pela perda dos recursos minerais, bem como por danos ambientais, ainda que potenciais, decorrentes dessa atividade. Porém, a maior parte das reservas da camada do pré-sal estão na plataforma continental, ou seja, são bens da União, nos termos do artigo 20 da Constituição Federal. Ademais, ainda no calor dos debates políticos sobre a destinação dos volumes financeiros advindos dos royalties, em especial entre estados e municípios detentores de petróleo e aqueles em que não há extração, surgiu a discussão sobre a destinação desses recursos para o atendimento de direitos sociais. 
É nesse contexto que foi promulgada a Lei $n$. 12.858 , de 9 de setembro de 2013, também conhecida como Lei dos Royalties do Petróleo, que regulamentou a destinação dos recursos oriundos dos royalties do pré-sal, encerrando, nesses termos, as disputas entre os entes federativos. Essa lei, em seu artigo 2으, afirma expressamente que 0 objetivo da destinação dos recursos é o cumprimento da meta prevista no inciso VI, do artigo 214 e no artigo 196, da Constituição. Os incisos I e II do

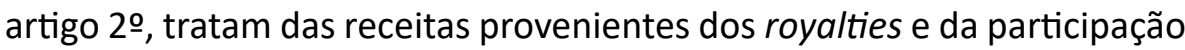
especial decorrente da extração do petróleo no pré-sal. O inciso III do mesmo artigo, afirma que serão destinados $50 \%$ dos recursos recebidos pelo Fundo Social, criado pela Lei n. 12.351/2010. A Lei dos Royalties do Petróleo determina, ainda, a repartição destes recursos na proporção de $75 \%$ para investimentos na educação e $25 \%$ para saúde.

Segundo Prado (2016), os repasses para educação poderiam chegar em 2022, quando se deve encerrar o atual PNE, em torno de R\$ 84 bilhões de reais, o que poderia ser um investimento extremamente significativo para políticas públicas educacionais. Porém, a exploração de recursos minerais como petróleo implica em complexas contradições sociais, econômicas e ambientais. Se por um lado a extração do petróleo gera grandes volumes de recursos financeiros, por outro é um recurso natural limitado. Além disso, sua extração e processamento causam, ainda que potencialmente, grandes riscos ambientais. Nesse sentido, para Bercovici (2011) os recursos gerados pela exploração do petróleo devem ser destinados à persecução de objetivos públicos, como a compensação de seus efeitos danosos, a justiça intergeracional e a democratização econômica.

As políticas públicas educacionais certamente são uma das formas mais proveitosas para investimentos de vultosos recursos como os oriundos do pré-sal. Em uma sociedade contraditória como a brasileira, a definição dos recursos públicos para efetivação de políticas e direitos sociais é decisiva para o desenvolvimento econômico e social do País. Porém, recentes alterações no regime de exploração do petróleo na camada pré-sal reduziram drasticamente as expectativas iniciais sobre os recursos que seriam destinados à educação e saúde. Essas alterações demonstram os embates que são travados em um setor estratégico 
para a economia e para o desenvolvimento social. Explicita também as dificuldades que ainda se enfrenta para destinação de recursos para financiamento de políticas públicas e efetivação de direitos sociais.

\section{CONSIDERAÇÕES FINAIS}

Procurou-se demonstrar a relação existente entre a afirmação dos direitos sociais e o surgimento das políticas públicas como meio para realização concreta desses direitos. Essas categorias surgem no contexto das transformações que ocorreram nos Estados, ampliando sua esfera de intervenção social e econômica. O Estado social não significa um "novo" Estado, mas a constituição de mecanismo institucionais que visam à efetivação de políticas de bem-estar e o atendimento às necessidades básicas da sociedade, em especial para grupos sociais vulneráveis.

As teorias liberais e suas repercussões no direito positivo foram importantes para afirmação de direitos de primeira geração, mas se demonstraram insuficientes logo em seguida, diante das novas reivindicações sociais, principalmente com os conflitos advindos com o capitalismo industrial. Isso se mostrou mais evidente com a crise econômica do final da década de 1920 e com as duas Guerras Mundiais. Os direitos sociais surgem, portanto, não como meras concessões parlamentares, inovações doutrinárias ou afirmações em tratados internacionais. Essa categoria de direitos, que marca o constitucionalismo do século $X X$, é resultado de profundas contradições e embates, da crise do liberalismo e da necessidade da intervenção estatal para o cumprimento de medidas sociais e econômicas.

Se, por um, lado as crises econômicas assolavam as parcelas mais vulneráveis da sociedade, por outro, as lutas reivindicatórias e os processos revolucionários, como no México (1910) e na Rússia (1917), para citar apenas duas experiências do início do século passado, provocaram mudanças que implicaram na afirmação dos direitos sociais. Não caberia ao Estado e ao direito apenas uma postura abstencionista, mas deveria agir no sentido da promoção de igualdades materiais. Necessidades básicas como moradia, alimentação, previdência social, proteção aos 
trabalhadores, saúde e educação, dentre outras, passam ao status de direitos, e são positivadas em normas constitucionais.

O Brasil acompanha esse processo de ampliação das funções do Estado e da afirmação de direitos sociais. Tendo como marco temporal a década de 1930, diversos direitos de natureza coletiva são incorporados ao texto das constituições. Desde 1934, a educação é elencada entre os direitos sociais mais relevantes. A educação ganhou destaque na Constituição de 1988, que não apenas estabeleceu diretrizes e sua organização como sistema nacional, mas especificou de forma detalhada metas orçamentárias. $\mathrm{O}$ financiamento das políticas públicas permanece como condição fundamental para efetivação dos direitos sociais. Porém, em 2005, ocorre algo que seria imprevisível quando da promulgação da Constituição, a descoberta do petróleo no pré-sal, que colocou o Brasil entre as maiores reservas petrolíferas do mundo.

Diante da potencial riqueza, passou-se a discutir a partilha dos royalties da exploração do petróleo no pré-sal. A solução proposta pelas Leis n. 12.351/2010, que criou o Fundo Social, e n. 12.858/2013, Lei dos Royalties do Petróleo, seria a destinação integral desses recursos para as áreas da educação e da saúde, com especial atenção à primeira. Seria a realização da promessa de efetivação do direito à educação no País?

No entanto, é na esfera da política que se tomam as decisões acerca dos direitos sociais e das políticas públicas. Nos últimos anos, principalmente a partir das eleições gerais de 2014, a política brasileira passa por um período de profunda crise, tendo como auge o impedimento, em 2016, da presidenta eleita democraticamente. Uma das primeiras medidas legislativas tomadas pelo Congresso Nacional, depois do processo de impeachment, foi a alteração do marco regulatório da exploração do petróleo no pré-sal, que implicou na diminuição considerável da distribuição dos royalties para educação.

Concluímos que a promessa constitucional, que remonta à década de 1930, efetivação material da educação como direito social permanece extremamente atual. As modificações legislativas da exploração do pré-sal realizadas no contexto da crise política brasileira, demonstram que a efetivação ou não do direito social à educação, por 
meio de recursos oriundos do petróleo brasileiro, ainda está indefinida. Será na arena da política, com suas contradições e interesses de grupos e classes sociais, que se decidirá a destinação dessa riqueza nacional. Esperamos que, conforme o projeto constituinte de 1988, a educação seja priorizada como condição necessária para construção do desenvolvimento socioeconômico nacional.

\section{REFERÊNCIAS}

ANDREOTTI, A. L. A administração escolar na Era Vargas e no nacional-desenvolvimentismo (1930-1964). Revista HISTEDBR [online], Campinas, $\mathrm{n}$. Especial, p. 102-123, ago. 2006.

BAUMAN, Z.; DONSLKIS, L. Cegueira moral: a perda da sensibilidade na modernidade líquida. Rio de Janeiro: Zahar, 2014.

BERCOVICl, G. Direito econômico do petróleo e dos recursos minerais. São Paulo: Quartier Latin, 2011.

BOBBIO, N. Norberto Bobbio: o filósofo e a política - antologia. Rio de Janeiro: Contraponto, 2003.

BONAVIDES, P. Curso de direito constitucional. 15. ed. São Paulo: Malheiros Editores, 2003.

BRASIL. Constituição 1988. Constituição da República Federativa do Brasil de 1988. Brasília, DF: Supremo Tribunal Federal, 2017. Disponível em: http://www.planalto.gov.br/ccivil_03/constituicao/constituicao.htm. Acesso em: 12 jun. 2018.

BRASIL. Lei $\mathbf{n} . \mathbf{1 2 . 3 5 1}$, de 22 de dezembro de 2010. Dispõe sobre a exploração e a produção de petróleo, de gás natural e de outros hidrocarbonetos fluidos, sob o regime de partilha de produção, em áreas do pré-sal e em áreas estratégicas; cria o Fundo Social (FS) e dispõe sobre sua estrutura e fontes de recursos; altera dispositivos da Lei n. 9.478, de 6 de agosto de 1997; e dá outras providências. Brasília, DF, 2010. Disponível em: http:// www.planalto.gov.br/ccivil_03/_Ato2007-2010/2010/Lei/L12351.htm. Acesso em: 12 jun. 2018. 
BRASIL. Lei n. 12.858, de 9 de setembro de 2013. Dispõe sobre a destinação para as áreas de educação e saúde de parcela da participação no resultado ou da compensação financeira pela exploração de petróleo e gás natural, com a finalidade de cumprimento da meta prevista no inciso VI do caput do art. 214 e no art. 196 da Constituição Federal; altera a Lei n. 7.990, de 28 de dezembro de 1989; e dá outras providências. Brasília, DF, 2013. Disponível em: http://www.planalto.gov.br/ccivil_03/_Ato2011-2014/2013/Lei/ L12858.htm. Acesso em: 12 jun. 2018.

BRASIL. Lei n. 9.394, de 20 de dezembro de 1996. Estabelece as Diretrizes e bases da Educação Nacional. Brasília, DF, 1996. Disponível em: http://www. planalto.gov.br/ccivil_03/leis/L9394.htm. Acesso em: 12 jun. 2018.

BUCCI, M. P. D. As políticas públicas e o direito administrativo. Revista trimestral de Direito Público. São Paulo: Malheiros Editores, 1996.

BUCCI, M. P. D. O conceito de política pública em direito. In: BUCCI, M. P. D. (org.). Políticas Públicas: reflexões sobre o conceito jurídico. São Paulo: Saraiva, 2006.

CHAUÍ, M. O que é política? In: NOVAES, A. O esquecimento da política. São Paulo: Agir, 2007.

DEMO, P. Política social, educação e cidadania. Campinas: Papirus, 1984.

GRINOVER, A. P. O controle de políticas públicas pelo Poder Judiciário. 2. ed. São Paulo: DPJ, 2009.

KERSTENETZKY, C. L. O estado do bem-estar social na idade da razão: a reinvenção do estado social no mundo contemporâneo. Rio de Janeiro: Elsevier, 2012.

MARTINS, R. M. Regulação administrativa à luz da Constituição Federal. São Paulo: Malheiros, 2011.

MEDAUAR, O. Serviços Públicos e Serviços de Interesse Econômico Geral. In: MOREIRA NETO, D. de F. (org.). Uma avaliação das tendências contemporâneas do direito administrativo. Rio de Janeiro: Renovar, 2003. 
MENDES, V. da R. Reflexões sobre os conceitos de homem, liberdade e Estado em Marx e as políticas educacionais. In: PARO, V. H. (org.). A teoria do valor em Marx e a educação. 2. ed. São Paulo: Cortez, 2013.

NUNES, A. J. A. As voltas que o mundo dá...: reflexões a propósito das aventuras e desventuras do estado social. Rio de Janeiro: Lumen Juris, 2011.

PEREIRA, C. P. Proteção social no capitalismo: contribuições à crítica de matrizes teóricas e ideológicas conflitantes. 2013. 307 f. Tese (Doutorado em Política Social) - Programa de Pós-Graduação em Política Social do Departamento de Serviço Social da Universidade de Brasília, DF, 2013.

PEREIRA, P. A. P. Discussões conceituais sobre Política Social como Política Pública e Direito de cidadania. In: BEHRING, E. et al. (org.). Política social no capitalismo: tendências contemporâneas. 2. ed. São Paulo: Cortez, 2009.

PRADO, F. A. B. B. Alteração legislativa dos royalties do pré-sal: efeitos sobre os princípios constitucionais e as políticas públicas. 2016. 120 f. Dissertação (Mestrado em Direito) - Programa de Pós-Graduação em Direito. Pontifícia Universidade Católica do Paraná, Curitiba, 2016.

WEBER, M. Ciência e política: duas vocações. 18. ed. São Paulo: Cultrix, 2011. 